Revista de Filosofía

ISSN: 0034-8244

http://dx.doi.org/10.5209/resf.72292

\title{
Protágoras: aparecer y ser en el marco de la praxis política
}

\author{
Lucas Manuel Álvarez
}

Recibido: 11 de febrero de 2019 / Aceptado: 19 de junio de 2019

Resumen. En el presente trabajo intentaremos poner en evidencia un singular enfoque sobre la pólis ateniense ofrecido por Protágoras en el diálogo platónico que lleva su nombre. Dicho enfoque, soslayado por los intérpretes, hace hincapié en la dimensión visual de la praxis política de los ciudadanos y es coherente con los posicionamientos ontológicos que emergen de los fragmentos del sofista.

Palabras clave: Protágoras; pólis; aidōs; phantasía; homo-mensura.

\section{[en] Protagoras: Appearance and being within the framework of political praxis}

\begin{abstract}
The present study aims to highlight the unique approach of the Athenian polis offered by Protagoras in the Platonic dialogue. This approach, ignored by most interpreters, emphasises the visual dimension of the political praxis of citizens and is consistent with the ontological positions that appear in the sophist's fragments.
\end{abstract}

Keywords: Protagoras; polis; aidos; phantasia; homo-mensura.

Sumario: I; II; III; Referencias bibliográficas.

Cómo citar: Álvarez, L.M. (2020): "Protágoras: aparecer y ser en el marco de la praxis política", en Revista de Filosofía 45 (2), 357-374.

1 Departamento de Filosofía Facultad de Filosofía y Letras Universidad de Buenos Aires lucasmalvarez@gmail.com 
Uno de los textos más extensos y explícitos que se conserva sobre el pensamiento político de los sofistas se encuentra en el diálogo Protágoras, donde Platón pone en boca del Abderita una larga intervención integrada por un mito, un pasaje explicativo y un razonamiento. Considerando los escasos fragmentos de Protágoras que han llegado hasta nuestros días, una de las cuestiones más controvertidas a la hora de abordar su pensamiento gira justamente en torno a ese testimonio platónico. En ese sentido, es posible soslayar dicho testimonio intentando reconstruir el pensamiento protagórico en base a materiales contemporáneos al sofista (como los de Anaxágoras, Demócrito, Eurípides o Zenón) ${ }^{2}$ o intentar descubrir al Protágoras histórico detrás del personaje de aquellos diálogos. Esta última es la estrategia que aquí adoptaremos, teniendo en cuenta no solo que la letra platónica es la fuente más copiosa para reconstruir las ideas protagóricas y que los intérpretes han logrado cierto consenso respecto a la autenticidad de la intervención del sofista, ${ }^{3}$ sino que además es posible identificar marcas textuales en el diálogo que, al vincularlas con los fragmentos conservados, podrían otorgarle autonomía al pensamiento del sofista frente a la crítica socrático-platónica. ${ }^{4}$

La intervención de Protágoras en el diálogo platónico es motivada por una discusión sobre la enseñanza de la arete $\overline{ }^{5}$ pero lo cierto es que lo expuesto por el sofista excede esa discusión, en la medida en que comporta una teoría política que se ocupa de los orígenes del hombre, de la ciudad y del Estado y ofrece ciertas consideraciones sobre el funcionamiento del sistema democrático. A pesar de que numerosas interpretaciones han puesto de relieve esas dimensiones, ${ }^{6}$ aquí creemos

\footnotetext{
Al respecto, véase Kulesz (2009), pp. 41-68.

Más allá de algunas voces que se han alzado en contra (véase Capizzi 1955, p. 259; Havelock 1957, pp. 4079; o van Riel 2012, pp. 145-7), los especialistas sostienen que i) el conjunto de la intervención mantiene una coherencia interna que sugiere la posibilidad de que haya sido incorporado de manera intacta (véase Schiappa 1954, p. 146), ii) Platón habría tomado las tesis de los propios escritos del Abderita (véase Adam 1905, p. xxii; Nestle 1944; Taylor 1976, p. 78; y Manuwald 1999, pp. 168-236, quien entiende que Platón pudo haber tomado el mito relatado por Protágoras de su escrito Peri Politeías donde el sofista habría desarrollado una historia mitológica para ilustrar el rol central de la politikē téchnē), iii) que la crítica platónica resulta más incisiva si lo dicho por el personaje Protágoras guardaba - a los ojos de los lectores - similitudes con el personaje histórico (véase Morgan 2000) y, por último, iv) la reproducida posición protagórica es abiertamente opuesta a la doctrina ética y política de la tradición socrático-platónica, sobre todo en lo que respecta a la participación política de los ciudadanos y a las diferencias entre las aretaí técnicas y políticas (véase Brisson 1975, p. 7 n. 2; y Solana Dueso 2011, p. 7, quien sostiene que "el mito y el discurso protagórico defienden esencialmente la diferencia entre la sabiduría para la vida y la virtud política. Ambas tienen origen distinto - Prometeo y Zeus - y corresponden a dos momentos diferentes de la experiencia histórica de la especie humana. Toda la argumentación platónica consiste en negar esa inecuación radical entre sabiduría técnica y política, es decir, en reducir la virtud política a ciencia”). Véase también Manuwald (2013), quien aduciendo otras razones también sostiene que el mito se basa en el Protágoras histórico.

$4 \quad$ Al respecto, véase Spangenberg (2009), pp. 70-2.

5 En el comienzo de Protágoras, Sócrates solicita al sofista que explique qué cosa enseña, y este responde que a todo aquel que acuda en busca de sus lecciones le enseñará a administrar de manera correcta la casa y los bienes familiares y, en cuestiones políticas, a ser el más capaz de la ciudad tanto en el obrar como en el decir (Protágoras 318d-319a). Sócrates infiere que Protágoras ha hecho profesión de enseñar la aretē política y, suponiendo que ello es imposible, le solicita que demuestre sus asertos de manera más clara. Sócrates objeta que a) en temas que se consideran enseñables (como, por ejemplo, la construcción naval), los atenienses solo escuchan el consejo de los expertos, pero que en lo que atañe a la política en general aceptan el consejo de todos (ya sea el de un carpintero como el de un herrero, el de un curtidor como el de un mercader), considerando que éste no es un asunto que requiera adiestramiento y b) que los mejores y más sabios hombres de Estado se consideran incapaces de transmitir su aretē a otros, incluyendo a sus propios hijos (Protágoras 319a-320b).

6 Entre las cuantiosas lecturas sobre los sentidos y objetivos del llamado "Gran Discurso" de Protágoras, pueden destacarse las de Nestle (1944, pp. 116-26), quien lee el mito como una teoría del origen de la cultura revestida
} 
que aún no se han destacado todos los sentidos que entrañan tanto el relato mítico como el pasaje explicativo y el razonamiento que lo suceden. Específicamente, entendemos se ha soslayado un determinado enfoque sobre la ciudad democrática planteado por el sofista, enfoque que hace hincapié en el rol de las apariencias que proyectan los ciudadanos en su praxis política. Por ello, a continuación intentaremos poner en evidencia esa visión protagórica que se despliega en tres operaciones sucesivas; a saber: i) la incorporación, en el mito, de la aidōs como condición de posibilidad de la ciudad; ii) la postulación, en el pasaje explicativo, de la necesidad de que los ciudadanos aparezcan participando de la justicia y iii) la descripción de la participación universal de esos mismos ciudadanos en la aretē política.

\section{I.}

En la versión ofrecida por el sofista, ${ }^{7}$ el mito de Prometeo comienza explicitando el modo por medio del cual los dioses forjaron a los mortales, encargándoles a dicho titán y a su hermano Epimeteo el reparto de las diferentes capacidades entre los seres vivos. Ahora bien, dado que Epimeteo deja incapacitados a los humanos, Prometeo busca alguna protección para ellos y roba a Hefesto y a Atenea el fuego junto con la "sabiduría técnica" (éntechnos sophía, Protágoras 321d1). Sin embargo, a pesar de esa donación, los hombres viven dispersos, a la merced de las fieras, y, por ello, intentando ponerse a salvo, se reúnen y fundan ciudades, aunque continúan pereciendo a causa de los ataques entre sí, de modo que nuevamente se dispersan y mueren. La razón de ese círculo vicioso estriba en la ausencia de la "técnica política" (politikē téchnē, Protágoras 322b8), ${ }^{8}$ técnica que depende de Zeus y que es entregada a los seres humanos a través de Hermes con el objeto de alcanzar orden en las ciudades y vínculos de amistad. A diferencia de las otras técnicas - en las que bastaba con que uno solo entre muchos las domine -, Zeus ordena que Hermes reparta la aidōs y la dikee entre todos para que todos participen de ellas, pues de lo contrario no habría ciudades. Asimismo, Zeus establece una ley: el incapaz de participar en la aretē política deberá ser eliminado como una "enfermedad para la ciudad" (nóson póleōs, Protágoras 322d5).

de lenguaje mitológico, Guthrie (1969, pp. 72-77), quien propone la antítesis nómos-phýsis y la discusión sobre los orígenes del Estado como los marcos general y particular en los que debe comprenderse el mito, Rodríguez Adrados (1975, pp. 172-180) para quien el relato mítico cumple con una definición de la naturaleza humana y Solana Dueso (2000, pp. 104-5), quien afirma que el mito se inserta en una tradición que busca explicar el origen del hombre, tradición a la que Protágoras le añade una preocupación por la fundamentación del sistema democrático y el origen del Estado. Esta última cuestión podría comprenderse como el esbozo de una teoría del contrato social, aunque Kerferd (1981a, pp. 147-8) advierte que la propuesta protagórica no puede asimilarse a un modelo contractualista, en la medida en que las voluntades particulares no asumen ningún rol de forma explícita. Finalmente, Bonazzi (2012, pp. 41-9) advierte que el mito relatado por el sofista no busca ser una reconstrucción histórica de los orígenes del hombre, sino que es una especie de parodia que toma elementos de esas reconstrucciones para su propio fin: el análisis de las notas distintivas de la naturaleza política del hombre. Sobre las distintas versiones griegas del mito, véase Dougherty (2006), García Gual (2009) y Calame (2012).

8 En el mito, Protágoras habla de una politikè téchnē (Protágoras 322b8), aunque luego, una vez acabado el mito, se refiere a una aretē politikē (Protágoras 322e2-a1). En ambos casos, la traducción del griego es dificultosa. Como bien señala Poratti (1999), las traducciones usuales de estos términos suelen decir justamente aquello que no son. Téchnē, traducido de manera usual como técnica o arte, no es ni una técnica en el sentido moderno del término (ligado al desarrollo mecánico y a la apropiación de la naturaleza) ni un arte si entendemos por ello algo vinculado a las "bellas artes". 
En esta versión protagórica del mito de Prometeo, las protagonistas indiscutibles son aidōs y díkē. En efecto, su donación no proviene de un mero titán como Prometeo, sino del propio Zeus, situación que, leída de manera simbólica y desacralizada, ${ }^{9}$ explica su preeminencia en el cuadro de las capacidades humanas, dado que son aidōs y dikē las que permiten nada menos que la estabilidad de las ciudades. Cabe preguntarse entonces en qué medida y por qué razones esas aretai garantizan, a los ojos del sofista, la subsistencia de una comunidad política, y para responder esa cuestión debemos desentrañar sus significados en el entramado del relato.

Por un lado, el término dike señala el campo de la justicia que viene a desplazar la fuerza y la hýbris del estadio en el que los hombres se atacan los unos a los otros. ${ }^{10}$ Sin embargo, no debemos pensar que esa justicia representa un cuerpo legal universal y definitivo aplicable a cualquier ciudad, sino, en todo caso, un sentido general de la justicia o de la norma que es particularizado por cada pólis. ${ }^{11}$ Además, teniendo en cuenta el contexto mítico en el que se inserta, esta díke tampoco debería comprenderse según las acepciones del siglo $\mathrm{V}$ que la vinculan a un tipo de castigo institucional, ${ }^{12}$ sino desde sus valores pre-homéricos que resaltan las ideas de 'costumbres' y 'usos' ${ }^{13}$ Si consideramos su condición no natural (a diferencia de las técnicas demiúrgicas, donadas antes de que los hombres salgan a la luz, la arete política no es natural ni innata, pues es otorgada por Zeus luego de la creación de los hombres), estos usos y costumbres propios de cada grupo representarían la cristalización de aquella larga experiencia de los hombres previa a la creación definitiva de las ciudades. Por último, es significativo resaltar, cierta dimensión visual de la diké, puesto que las normas y usos que ella supone son aquellos que el ciudadano debe exhibir en público, según lo advierte Cassin. ${ }^{14}$

En el caso de la aidōs resulta fructífero comenzar considerando el antecedente hesiódico del mito. En Trabajos y Días, el poeta también menciona de forma conjunta los términos aidōs y díkē, pero subraya la ausencia del primero, advirtiendo que si bien entre los hombres existe la justicia entregada por Zeus (y no así entre las fieras), la Aidōs, en cambio, los ha abandonado marchándose al Olimpo. ${ }^{15}$ Habida cuenta de cierta filiación entre esta versión y la protagórica ${ }^{16}$ llama la atención ese abandono de la aidōs en la primera, y dado que su incorporación representaría una

9 Solana Dueso (2000,pp. 99-121), propone una novedosa lectura simbólica que cuestiona tanto las interpretaciones literales como aquellas que creen ver en las intervenciones divinas puros adornos retóricos. En su lectura, el mito relatado por Protágoras incorpora una novedad fundamental respecto de la versión de Esquilo: Prometeo y sus artes son superados (al no garantizar la supervivencia del género humano) por el arte de la política que es patrimonio de todos y asegura esa supervivencia al provenir de un origen más elevado, el de Zeus. Cabe remarcar que tradicionalmente los griegos retrataban a Zeus como el garante de la justicia. Al respecto, véase Denyer (2008), p. 108.

10 Véase Solana Dueso (2000), p. 117.

11 Al respecto, Sørensen (2016), pp. 117-8. Recordemos lo que Sócrates le hace decir a Protágoras en su apología en el diálogo Teeteto: "lo que a cada ciudad le parece justo (dikaia) y honorable, es así para esa ciudad, por el tiempo que así lo juzgue" (167c). La traducción le corresponde a Boeri (2006) aquí y en citas ss.

12 Véase Saxonhouse (2006), p. 68.

13 Véase LSJ s.v. 'dike '.

14 Cassin (1994), pp. 91-2.

15 En primer lugar, luego del aniquilamiento de la quinta raza, Hesíodo afirma que "la justicia (díkē) estará en la fuerza de las manos y no existirá aidōs" (v. 193); en segundo lugar, se especifica que es entonces cuando "Aidōs y Némesis [...] irán desde la tierra de anchos caminos hasta el Olimpo para vivir entre la tribu de los Inmortales, abandonando a los hombres" (v. 200). La traducción le corresponde a Jiménez (2000) aquí y en citas ss.

16 Decleva Caizzi (1999, p. 319), considera que el sofista parece estar adaptando la narración hesiódica a su tiempo. 
innovación del sofista, los sentidos que ella comporta son clave para comprender el funcionamiento de la aretē politikē como condición de posibilidad de la ciudad.

Puede señalarse ante todo que la presencia de la aidōs en el relato de Protágoras es coherente con el contexto mítico en el que se inserta debido a la dimensión arcaizante y poética del término. ${ }^{17}$ Por esa razón, ya en el pasaje explicativo, esa aidōs será reemplazado por un término que ya no resulta anacrónico. Hablamos de sōphrosýne que indica el buen juicio, el auto-control y la prudencia ${ }^{18}{ }^{18}$ una prudencia que opera mediante el dominio de sí que le impide a su poseedor hacer todo aquello que desea, en la medida en que entiende que la satisfacción de algunos de esos deseos será vergonzosa o violará las normas sociales. ${ }^{19}$ Esos sentidos ya se encuentran implícitos en la misma noción de aidōs. Derivado del verbo poético aídomai, aidōs es un sustantivo que expresa el respeto o la reverencia que existe, por un lado, entre los dioses y, por el otro, en los hombres ante los dioses. ${ }^{20}$ Como virtud moral y cívica, puede referirse a la acción de refrenarse y, finalmente, puede expresar la vergüenza ante la opinión ajena y el sentido del honor. ${ }^{21}$

Cairns entiende la aidōs como una emoción inhibitoria de la acción que, teniendo en cuenta las normas ideales de la sociedad, protege la propia imagen ante la mirada de los otros. Además, sugiere que, en los dramaturgos y pensadores del siglo V, el concepto comienza a interactuar de manera creciente con el mecanismo autoregulador e internalizado de la conciencia y a vincularse con la cuestión de las acciones realizadas en secreto. ${ }^{22} \mathrm{~A}$ la hora de proponer una traducción, el mismo Cairns entiende que los sentidos de la aidōs no pueden asimilarse con ningún concepto de nuestra cultura moderna, aunque advierte que existe una noción que puede ayudarnos a tomar contacto con esa particular experiencia griega. El autor se refiere a la idea de vergüenza que, en su equivalencia parcial con aidōs, comparte características sustanciales: ambos conceptos suponen la presencia de un otro (de una especie de audiencia real o imaginaria), ambos están asociados con la cuestión de la visibilidad y la mirada del otro y ambos entrañan ciertos patrones de conducta que involucran la evasión de dicha mirada. ${ }^{23}$ Esta estrecha relación entre la aidōs y la visión es confirmada por Aristóteles, quien en Retórica sostiene que " $<$ se siente vergüenza $>$ de lo que está a la vista y es más ostensible (de donde el proverbio: en los ojos está la vergüenza [aidō])" (Ret. 1384a 33-4). Como sugiere Grimaldi, el proverbio del que se hace eco el Estagirita indica que la vergüenza reside en aquellos actos que se hacen públicos, en aquellos actos que son vistos por los otros. ${ }^{24}$

En el caso particular del diálogo platónico, las traducciones que se han ofrecido del término aidōs incorporado por Protágoras son abundantes y disímiles, ${ }^{25}$ pero, a

\footnotetext{
Al respecto, véase Cairns (1993), p. 175 n.100; (2010), pp. 297-8; y Williams (1993), p. 194 n. 9.

Véase LSJ s.v. 'sōphrosýne'.

19 Taylor (1976, pp. 85-6), considera que 'aidōs' es prácticamente un sinónimo de 'sōphrosýnē'. Por su parte, García Gual (1982, pp. 526-7 n. 31), se opone a esa equivalencia.

20 Véase Chantraine (1999), p. 31.

21 Véase DGE s.v. 'aidōs'.

22 Cairns (1993), pp. 48-146.

23 Cairns (1993), pp. 14-5. Desde el campo de la psicología, la vergüenza ha sido asociada con el deseo de esconderse, con el deseo de sustraerse de la mirada de los otros. Al respecto, véase Tangney (1991), pp. 598607. Cabe destacar que en el diálogo Fedro, Platón apela a la noción de aischýne (Fedro 237a5) (noción que, como veremos más adelante, resulta equivalente a la de aidōs) para señalar la vergüenza que siente Sócrates frente a Fedro y el deseo de sustraerse a su mirada (le pide continuar la conversación con el rostro cubierto).

24 Grimaldi (1988), p. 117.

25 Por ejemplo, Croiset y Bodin (1948, p. 37), se han inclinado por 'pudeur'; Guthrie (1956, p. 54), por 'respect
} 
nuestro entender, no alcanzan a recuperar la constelación de sentidos que abarca el concepto. La excepción es Ildefonse quien, al optar por 'vergogne', permite reinstalar aquella constelación. ${ }^{26}$ Siguiendo entonces la propuesta de la traductora francesa, podemos afirmar que, mediante la incorporación de la aidōs, el sofista subraya la importancia de la mirada de los otros en el campo de las incipientes relaciones sociales. Desde la óptica de Protágoras, la dike es una condición necesaria, pero no suficiente para el sostenimiento de las ciudades y por ello incorpora y mantiene la aidōs. Esta termina de asegurar la pervivencia de la ciudad sellando la pertenencia de sus miembros a través de una red de miradas que cubren los espacios públicos (tanto institucionales como no-institucionales) ${ }^{27}$ y regula la adhesión a los valores comunales. ${ }^{28}$ Los hombres dejan de atacarse entre sí por dos razones concomitantes: porque las miradas de todos gravitan sobre las acciones y las apariencias de todos y porque cada uno de ellos actúa para los otros sabiendo que, en simultáneo, esos otros actúan para él. Por lo tanto, aquel aspecto visual que apenas se insinuaba en el caso de la dike cobra ahora su real dimensión operando por medio de un doble movimiento: la proyección de una imagen de sí mismo y el escudriñamiento de esa imagen por parte de los otros.

En el relato mitológico, Protágoras parece establecer un juego de interdependencias entre la aidōs y la dikēe. La inhibición de la acción que supone la primera necesita de la dike (tanto la proyección de apariencias como las miradas reguladoras se atienen al acervo de usos y costumbres de cada comunidad), mientras que esta última necesita de la aidōs para ser efectiva (el conjunto de esos usos y costumbres solo puede mantenerse si los sujetos lo exhiben en público al tiempo que les exigen a sus pares la misma exhibición). Como puede notarse, aidōs y dikē representan para el Abderita las habilidades básicas y necesarias de la interacción social, y en ellas la dimensión visual cumple un papel decisivo. ${ }^{29}$ Sin embargo, tal dimensión solo puede comprenderse de forma cabal si se estudia el pasaje explicativo dispuesto a continuación del mito donde la importancia de lo visual es explicitada y ratificada.

for others'; Chambry (1967, p. 53), también por 'pudeur'; Taylor (1976, p. 14), por 'conscience'; García Gual (1982, p. 526), por 'sentido moral'; Ildefonse (1997, p. 87), por 'vergogne'; Divenosa (2006, p. 138), por 'vergüenza' y Arieti \& Barrus (2010, p. 56), por 'reverential fear'.

26 Ildefonse (1997), p. 87. Mondolfo (1955), p. 536, sugiere que en el mito la traducción correcta de aidōs sería "sentimiento o conciencia moral", aunque advierte que el término conserva los sentidos de "pudor, respeto y vergüenza", una vergüenza que se experimenta no solo ante los demás sino ante uno mismo.

27 Al hablar de "espacios públicos" seguimos la propuesta de Gottesman (2014, pp. 4-26), quien recuperando los enfoques acerca de la public sphere desde los aportes de Habermas hasta las discusiones contemporáneas sobre el caso griego, propone dos tipos de esferas públicas: las institucionales (la del Consejo, la Asamblea, los tribunales y el teatro) y las no-institucionales (la de las diversas asociaciones y grupos en los que se organizaban los antiguos griegos). A juicio de Gottesman, lo que tienen en común sendas esferas es que a través de ellas fluye el discurso, aunque, a los ojos de Protágoras - tal es nuestra hipótesis -, también fluyen a través de todas ellas las apariencias.

28 Si tenemos en cuenta la propuesta de Benveniste (1969, pp. 340-41), sobre la íntima vinculación entre philía y aidōs (los aliados, los parientes, los amigos y todos aquellos que están unidos por deberes recíprocos de aidōs son considerados phíloi), podríamos pensar que al hablar de la aretē enviada por Zeus como aquella que asegura las "ligaduras acordes de amistad" (Protágoras 322c) el sofista se está refiriendo a esa red de miradas articulada por la aidōs. Ahora bien, en la versión hesiódica del mito de Prometeo las ligaduras juegan un papel represivo y violento, pues Zeus castiga al titán con "irrompibles ligaduras" (Teogonía 522). Y en sintonía con ello, el propio Protágoras habla de una ley por la cual los hombres incapaces de participar de la aretē política deberían ser eliminados como una "enfermedad para la ciudad" (Protágoras 322c-d). La ciudad parece depender de tal manera de la internalización ciudadana de la aidoss, que aquel que no se encuentra ligado por esa red de miradas que le hace respetar los usos y costumbres es considerado como una plaga que debe, eventualmente, ser expulsada de la comunidad.

29 Sobre aidōs y dikē como habilidades básicas de la interacción social, véase Manuwald (2013), p. 174. 


\section{II.}

Si en la primera sección de su discurso el sofista se ocupa de un supuesto tiempo primigenio (apelando a un mito como símbolo del estatus epistemológico de la hipótesis que maneja), en la segunda sección parece ocuparse de una ciudad real y de la práctica cotidiana de sus ciudadanos y, en consonancia con ello, abandona el género mitológico y ofrece un pasaje que explica y aplica lo dicho en el mito. En ese sentido, habiendo establecido la participación de todos los ciudadanos en la aretē política, Protágoras comienza la nueva sección señalando que ahora pueden entenderse las razones por las cuales los atenienses (ya no se habla de cualquier hombre, sino de los ciudadanos de Atenas) no excluyen a nadie cuando se trata de discutir sobre alguna cuestión relativa a esa aretē, mientras que si se trata de algún tema referido a las aretai profesionales solo aceptan la opinión de unos pocos. Y, reforzando esa idea, afirma que

en la justicia (dikaiosýnēe y en la restante excelencia política (politikē aretē), si saben que alguno es injusto (eidōsin hóti ádikos estin) y éste, él por su propia cuenta, habla con sinceridad en contra de la mayoría, lo que en el otro terreno se juzgaba sensatez (sōphrosýnēn), decir la verdad, ahora se considera locura, y afirman que delira el que no aparenta ser justo, lo sea o no (phánai eînai dikaious, eánte ôsin eánte mē). De modo que parece necesario que nadie deje de participar de ella en alguna medida, bajo pena de dejar de existir entre los humanos (Protágoras 323b2-c2). ${ }^{30}$

En las líneas citadas, Protágoras deja entrever que los atenienses efectúan una distinción entre los espacios propios de cada tipo de aretē, distinción que se verifica por una inversión de sentidos: lo que se considera sensatez en un espacio se entiende como locura en el otro y viceversa. Asimismo, en este punto del discurso, se sustituye de manera subrepticia aidōs y dikee por sōphrosýnē y dikaiosýnēe, un cambio de términos que responde al cambio de contextos (de uno mítico a uno argumentativo). No obstante, más allá de ese cambio, la dimensión visual que comportaban los términos suplantados es ahora reinstalada por medio de dos verbos que estudiaremos a continuación.

En el caso de la aretē política, lo primero que señala el Abderita es que se decreta locura una vez que los ciudadanos saben que alguien es injusto, y el verbo utilizado para referirse a ese eventual conocimiento es ồda. Los sentidos de este verbo un perfecto con valor resultativo, cuya forma reconstruida del presente es eído implican saber, pero un saber por 'haber visto'.$^{31}$ En nuestro caso, ồda señala un saber que resulta de la exhibición que alguien efectúa respecto de su condición injusta. Por lo tanto, la dimensión visual de la aidōs reaparece con este verbo que pone nuevamente en juego el doble movimiento que suponía dicha dimensión: la proyección de apariencias que genera un agente y las miradas de sus pares que la evalúan. Cabe señalar que esta proyección y aquel conocimiento que supone el verbo ốda cobran sentido en la arena pública, donde es posible que un ciudadano

\footnotetext{
30 La traducción, con algunas modificaciones, le corresponde a García Gual (1982) aquí y en citas ss. En los casos en que traducimos el término aretē preferimos hacerlo apelando no a 'virtud', sino a 'excelencia', siguiendo el DGE s.v. 'arete'.

31 Véase LSJ s.v. 'eidō'.
} 
se muestre y hable ante 'muchos' (polús, Protágoras 323b4) y, llegado el caso, sea considerado loco al pronunciarse contra esa mayoría.

El segundo verbo sobre el que quisiéramos detenernos es aquel que utiliza Protágoras al afirmar que los atenienses le adscriben locura a aquellos que no "aparentan" (phánai, Protágoras 323b6) ser justos. El verbo phaínein puesto en boca del sofista merece nuestra atención, en la medida en que el concepto de phantasía, vinculado a dicho verbo, irrumpe en el ámbito filosófico justamente de la mano del Abderita. El sustantivo phantasía deriva del verbo en voz media phantázomai (que significa 'volverse visible', 'aparecer'), verbo que, a su vez, se vincula con pháinō, cuyos sentidos son 'traer a la luz', 'manifestar' y, en voz media, 'hacerse visible', 'dejarse ver'. ${ }^{32}$ En el contexto del pensamiento griego antiguo, el concepto de phantasía involucra tanto la apariencia de algo como la presentación o aparición de eso mismo a un sujeto, a su conciencia, memoria o sentidos. ${ }^{33}$ De esta forma, el concepto se ubica en un espacio objetivo-subjetivo que no se reduce ni al campo de los fenómenos ni tampoco al campo de la actividad psíquica, sino que opera en una zona de interacción entre sujeto y mundo. ${ }^{34}$

Ahora bien, si nuestra intención es comprender los sentidos que podría adquirir esa phantasía en el pasaje que estamos estudiando, resulta insoslayable la lectura de la sentencia protagórica de la homo-mensura. ${ }^{35}$ En el diálogo Teeteto, Sócrates nos dice:

Sostiene [Protágoras] que el hombre es «medida de todas las cosas, de las que son en cuanto son, de las que no son en cuanto no son» (pántōn chrēmátōn métron ánthrōpon ê̂nai tôn mèn óntōn ōs ésti, tôn dè mē óntōn ōs ouk éstin) [...] ¿Y no está diciendo algo así como que las cosas particulares son para mí tal como me (a)parecen (phaínetai), y que para ti son tal como se te (a)parecen" (Protágoras 152a2-6). ${ }^{36}$

Aunque no es nuestra intención ofrecer aquí un análisis detallado del dictum, debemos decir algunas palabras sobre el controvertido significado de sus términos claves - chrêma, métron, ánthrōpos y ōs - antes de ocuparnos del rol de la phantasía. Con respecto a chrêma, existe un cierto consenso según el cual el término hace referencia a las cosas en tanto se vinculan con alguien, ${ }^{37}$ tà chrêmata estaría señalando entonces aquellas cosas con las que trata o de las que se vale el ánthrōpos. ${ }^{38} \mathrm{El}$ término métron comporta los sentidos de 'medida' o 'regla' que el hombre aplicaría a aquellas cosas. ${ }^{39} \mathrm{~A}$ juicio de van Berkel, el dictum protagórico estaría reaccionando

\footnotetext{
Véase LSJ s.v. 'pháinō'.

$\mathrm{Ib}$.

Véase Díaz, Livov y Spangenberg (2009), pp. 29-30.

La vinculación entre lo dicho por Protágoras en el diálogo platónico homónimo y su tesis de la homo-mensura no está muy extendida en la bibliografía especializada. Al respecto, véase Sørensen (2016), pp. 100-1.

36 La traducción le corresponde a Boeri (2006) aquí y en citas ss. Con la grafía "(a)pariencia” el traductor pretende recuperar la valencia doble del término, i.e. el valor fisiológico de "aparece", "se presenta" y el cognitivo de "parece que".

37 Véase Versenyi (1962) y Cassin (1995), p. 229.

38 El término no parece referirse solo a las cosas visibles objetos de nuestra percepción, sino también a aquellas cosas que involucran cuestiones del ámbito ético-político (como lo justo y honorable que el mismo Sócrates incorpora en el diálogo. Véase Teeteto 167c).

39 Véase LSJ S.v. 'métron'. Teniendo en cuenta la raíz compartida con el término $\mu \varepsilon ́ \delta \omega$ (cuyos sentidos son los de 'proteger' o 'gobernar sobre'. Véase LSJ s.v. 'médō’) Untersteiner (1949-67, pp. 117-123) ha sugerido que la noción de métron supone cierta carga normativa y que, por ello, implicaría la idea de un dominio ejercido por el
} 
frente a la tradición arcaica y presocrática según la cual el hombre adquiere las normas y las medidas de lo real, pues, bajo la mirada del Abderita, el hombre sólo proyecta sus propias medidas..$^{40}$ Por su parte, el sustantivo ánthrōpos goza de una ambigüedad que lo hace capaz de ser leído en sentido individual (un hombre singular para quien el viento es frío), genérico (el hombre como especie que impone su medida a diferencia de, por ejemplo, la medida que impondría un cerdo) o colectivo (el hombre como ciudadano).$^{41}$ Por último, en la sentencia se indica que ese hombre es medida de las cosas con las que trata 'en cuanto' ( $\bar{s} s)$ son y 'en cuanto' ( $\bar{o} s)$ no son. Y a la hora de traducir $\overline{o s}$ los intérpretes han optado o por la conjunción 'que' (lo que supondría que el hombre es medida de la existencias de las cosas, ya que $\bar{o} s$ no implicaría cualificación alguna), o por 'como' (lo que supondría que el hombre es medida de la cualidad de esas cosas dada la elección de un adverbio de modo) o bien por ambas (Untersteiner ha sugerido que $\bar{o} s$ debe entenderse simultáneamente en ambos sentidos, pues la diferencia entre el 'que' y el 'como' solo es abstracta: la existencia de las cosas implican ya su manifestación). ${ }^{42}$

Esclarecidas las variantes de lectura de cada uno de los términos, el dictum protagórico se deja ver dueño de una singular ambigüedad de la que emerge la figura de un hombre - ya sea individual o colectivo - medida de la existencia o de las cualidades de las cosas que le conciernen..$^{43}$ Ahora bien, si seguimos leyendo la letra platónica, es posible pensar que dicha medida se encuentra signada por la phantasía. En efecto, Sócrates advierte que el sofista habría querido decir que "las cosas particulares son para mí tal como me (a)parecen (phaínetai), y que para ti son tal como se te (a)parecen" (Teet. 152a6-8). En esta explicación, Sócrates no utiliza la expresión tà chrêmata, pero si seguimos el orden del dictum pareciera que la phantasía de la que habla es la que media entre ánthrōpos y chrêma. Se ha pensado que los resultados de la sentencia implican conclusiones anti-ontológicas, en la medida en que la prioridad de la phantasía podría suponer que no hay ninguna cosa en sí, sino que todas las cosas son en relación con el hombre y su parecer. ${ }^{44}$ Sin embargo, a nuestro juicio la tesis de la homo-mensura no supone una posición estrictamente anti-ontológica, lo que puede afirmarse al recuperar no solo las variantes de lectura de la sentencia, sino también al vincularla con el Gran Discurso que Protágoras ha ofrecido en el diálogo homónimo.

Como puede observarse, el término que encabeza la sentencia es chrêmata - y no ónta - lo que daría a entender, desde un principio, que su alcance está circunscripto a las cosas en tanto estas se vinculan con el hombre. Asimismo, los términos de esa vinculación están signados por el posible significado adverbial de ōs (que implica un vínculo entre el hombre y la cualidad o el modo de esas cosas) y luego, gracias a la explicación socrática, por la incorporación de la phantasía (que podría estar limitando el significado de aquellas chrêmata a los fenómenos). El hombre, por lo

hombre sobre las cosas. Contra esa interpretación se opone Capizzi (1955), p. 108.

40 En ese sentido, van Berkel (2013, p. 61), vincula la sentencia de Protágoras con la crítica de Jenófanes a la concepción antropomórfica de los dioses (Véase DK21B11).

41 Defienden la primera alternativa Guthrie (1969), p. 173, y Kerferd (1981a), p. 86, entre otros, la segunda alternativa es apoyada por Gomperz (1893), p. 451, y la tercera por Dupréel (1948), p. 25, y Caujolle-Zaslawsky (1986), p. 157

42 La primera opción es defendida por Masfeld (1981), la segunda por Classen (1989) y la última por Untersteiner (1949).

43 Zilioli (2007), p. 34, habla de una ambigüedad "oracular".

44 Al respecto, véase Spangenberg (2009), pp. 84-9. 
tanto, resulta una medida de la cualidad con que las cosas se presentan o del modo de las cosas con las que trata y esas cosas no son más que apariencias. Si este es el caso, el dictum no estaría planteando una especie de adherencia entre "las cosas en sí" y la phantasía (adherencia que disolvería la instancia del ser en la del aparecer), sino que, desde una posición más bien prudente, estaría señalando los límites del ámbito humano, el de los fenómenos, y proponiendo hacer silencio sobre el resto. ${ }^{45}$

Asimismo, ese silencio podría rastrearse en otro de los fragmentos del sofista, aquel en el que se abstiene de hablar sobre los dioses, y que Diógenes Laercio nos transmite del siguiente modo:

Sobre los dioses no puedo saber ni si existen ni si no existen ni tampoco cómo son en su forma externa (perì mén theôn ouk èchō eidénai, oýth'ōs eisin oýth'ōs ouk eisin oýth 'hopoîoi tines idéan). Ya que son muchos los factores que me lo impiden: la oscuridad (adēlótēs) del asunto así como la brevedad de la vida humana" (DK80 B4). ${ }^{46}$

Más allá de la existencia de cierta analogía estilística entre este fragmento y la sentencia de la homo-mensura, ${ }^{47}$ aquí nos interesa señalar que el agnosticismo de Protágoras podría ponerse en paralelo con aquel silencio del que hemos hablado. De hecho, mientras que, en este fragmento B4, el sofista aclara que no puede pronunciarse sobre la existencia o no existencia de los dioses (tanto por factores objetivos - la oscuridad del asunto - como por factores subjetivos - la brevedad de la vida del hombre -), en B1 parece abstenerse de hablar sobre el hombre como medida de la existencia o no existencia de las cosas.

Ahora bien, si B1 parece referirse a las cualidades y modos de las cosas que están en relación con el hombre y esta relación se funda en la phantasía, en B4 - luego de aclarar que nada puede decirse sobre la existencia de esos dioses - se añade que incluso nada se sabe de su forma externa (idéa). Frente al caso de B1, aquí el silencio es mayor, en la medida en que ni siquiera puede saberse cómo es esa forma externa, puesto que aquellos seres no se le aparecen al hombre. Cabe destacar que el Abderita utiliza una forma del verbo ồda (el infinitivo perfecto eidénai) para señalar el desconocimiento que el sujeto enunciador tiene acerca de los dioses, mientras que en el pasaje explicativo del mito de Prometeo se utiliza el mismo verbo para indicar el conocimiento que los politai tienen de sus pares. Si en aquel caso se conocía por haber visto, en este caso se desconoce porque nada se puede ver. Asimismo, tal desconocimiento resulta ratificado en este fragmento por el adjetivo àdèlos - que comporta el sentido de 'dudoso' e 'incierto', pero también de 'invisible' y 'oscuro' $-{ }^{48}$ que se incorpora para confirmar la invisibilidad, la no-aparición, de los seres divinos. $^{49}$

Finalmente, estamos en condiciones de vincular nuestro análisis de los fragmentos B1 y B4 con el pasaje explicativo del diálogo platónico, vinculación que nos permitirá

45 Véase Rossetti (1985), p. 188, quien vincula esa limitación protagórica con la proposición de Wittgenstein acerca del silencio que debe practicarse sobre las cosas de las que no puede hablarse.

46 La traducción le corresponde a Melero Bellido (1996) con algunas modificaciones. El fragmento también es citado por Sexto Empírico (DK80A12), Cicerón (DK80A23) y Eusebio (DK80B4), y además parafraseado por Filóstrato (DK80A2), Filodemo (DK80A23) y Platón (Teeteto 162d).

47 Sobre tal analogía, véase Capizzi (1955), p. 119.

48 Véase DGE s.v. 'àdēlos'.

49 Con respecto a esta interpretación del adjetivo en el contexto de la sentencia, puede consultarse la traducción y el comentario ofrecidos por O’Brien en Sprague (1972), p. 20. 
ofrecer una última prueba tanto del silencio sobre el plano ontológico como de la preeminencia de la dimensión visual en el enfoque protagórico sobre la ciudad. En el pasaje explicativo, el sofista sostiene que, en el marco de la aretē política, los ciudadanos "afirman que delira el que no aparenta ser justo, lo sea o no (phánai eînai dikaious, eánte ôsin eánte mē)" (Protágoras 323b6). Evidentemente, la fórmula final de esta línea (con su lógica de opuestos) es similar a la utilizada tanto en B1 como en B4 - en esos casos para referirse a las cosas y a los dioses respectivamente y aquí para hablar de los ciudadanos - $\mathrm{y}$, además, a esta fórmula que cuenta con usos del verbo eimí se le opone, al igual que en B4, un plano del aparecer. Pero ¿qué implica esa afirmación en la explicación del funcionamiento de la ciudad?

Partiendo del análisis conjunto de su intervención en el diálogo platónico y de sus fragmentos, aquí pensamos que Protágoras podría estar sugiriendo que, en el terreno de la aretē politikē, es decir, en la arena pública de una ciudad, no es suficiente ser mínimamente justo (recordemos que en el contexto del Gran discurso eso significaría participar mínimamente de los valores comunales), sino que es necesario aparecer como justo. El no participar al menos de manera mínima en la justicia representaría una anomalía - porque, según hemos visto, Zeus entrega la aretē politikē a todos -, pero Protágoras deja ese plano en un estado de indeterminación que es articulado mediante el uso del verbo ser en modo subjuntivo y reforzado por la partícula eán. Por el contrario, y gracias a una lúcida observación del funcionamiento de la ciudad, el sofista sugiere que esa incertidumbre debe eliminarse en el plano del aparecer: sea o no sea justo (de ello nada puede decirse), el politēes está obligado a aparecer como tal, pues de no hacerlo será catalogado como un loco y perderá su lugar entre los hombres. Ese castigo parece implicar una expulsión de la comunidad política y de ahí la incorporación de la locura, una figura de la otredad. ${ }^{50} \mathrm{Al}$ no ser permeable a la red de miradas que impone la aidōs, al perder el 'buen juicio' que supone la sōphrosýne, el loco se convierte en un otro respecto del cuerpo ciudadano.

En este punto, ya pueden unirse los tres razonamientos del sofista: i) el hombre no es medida de la existencia o no existencia de las cosas, sino de su aparecer, ii) de la existencia de los dioses nada puede decirse porque estos no aparecen ante los hombres, iii) la condición de un ciudadano no depende de su ser o no ser justo, sino de su aparecer como justo. El silencio acerca del plano ontológico une la epistemología con la teoría política. Y en esa teoría, la phantasía resulta prioritaria, pero no niega la existencia de un objeto al margen del fenómeno, sino que evidencia el particular funcionamiento de la ciudad que se rige por los apareceres de los ciudadanos. Como hemos intentado mostrar, los verbos phaínein y oîda utilizados en el pasaje explicativo del Gran Discurso reiteran los sentidos que imponía la aidōs en el contexto mítico: todos implican la primacía de las miradas, de la visibilidad y del cuidado que cada uno de los ciudadanos deposita en la proyección de su propia imagen. El ciudadano-agente procura mostrarse justo sabiendo que así satisface las expectativas de sus pares, mientras que el ciudadano-espectador escudriña y controla las apariencias de los otros. Ambas funciones (la de agente y la de espectador) son, no solo intercambiables, sino también simultáneas: un ciudadano observa al mismo tiempo que se muestra y viceversa.

Si antes habíamos afirmado que los hombres dejaban de atacarse entre sí, en la medida en que actuaban para los otros sabiendo que, en simultáneo, esos otros

50 Sobre las posibles lecturas de esa afirmación protagórica, véase Ildefonse (1997), p. 172 n. 130. 
actuaban para ellos, ahora podemos añadir que cada uno de los ciudadanos muestra de sí lo que sabe que el otro espera que muestre, es decir, representa un papel convenido. El enfoque de Protágoras se termina de trazar: en Atenas, donde cada ciudadano cumple de manera intermitente los roles de agente de apariencias y espectador de apareceres, el espacio público hace las veces de gran escenario donde los actores deben aparecer participando de los valores comunales. ${ }^{51}$

\section{III.}

Una vez concluido el pasaje explicativo del mito, el Abderita añade un razonamiento sobre la enseñanza de la arete advirtiendo que esta es impartida tanto por padres, madres y nodrizas al mostrarles a los niños "que esto es justo (dikaios) y aquello injusto (ádikos), que eso es hermoso (kalós), y eso otro vergonzoso (aischrós), que una cosa es piadosa y otra impía" (Protágoras 325d), por los maestros (quienes presentan encomios de hombres virtuosos) como por la propia ciudad que obliga a sus ciudadanos a aprender y a vivir de acuerdo con las leyes. Y a partir de la descripción de esa enseñanza universal de la aretē, Protagóras infiere que todos son mínimamente capaces en ella, a diferencia de los salvajes presentados en la comedia de Ferécrates que nada saben ni de leyes ni de tribunales. ${ }^{52}$

Ante todo, es de notar el uso del adjetivo aischrós entre aquellos valores que se les enseñan a los niños, adjetivo que comparte el campo semántico de la aidōs, y si bien aischrós puede referirse a la fealdad de una apariencia externa, lo cierto es que además significa aquello digno de vergüenza o deshonra. ${ }^{53}$ Aidōs comprende los sentidos que el sofista necesita para su hipótesis sobre los tiempos primigenios y aischrós es el término prosaico que elige para dar cuenta de una práctica cotidiana de los atenienses, pero ambos señalan la presencia de la otredad a través de sus miradas y el manejo de lo que se aparenta o proyecta frente a esas miradas.

Un uso significativo del adjetivo aischrós que apela a esos sentidos que estamos señalando - presente en un texto de clara raigambre sofística e incluso, según algunos intérpretes, protagórica - es aquel que aparece en Dissoì Lógoi ${ }^{54}$ En la primera parte

51 Podría pensarse que los enfoques protagóricos se vinculan con las novedosas tendencias estéticas del siglo V a.C. que en la arquitectura, la escultura, la pintura y el teatro privilegiaban el aparecer y la mirada del espectador. Según sugiere Goux (1990, pp. 125-58), en el paso de la aspectiva a la perspectiva, las artes griegas se inclinaron no hacia la precisión empírica, sino hacia la producción de maravillas que se ajustaban a la particular visión del espectador. Entonces, así como un edificio, una pintura, una escultura o una pieza teatral se construyen teniendo en cuenta esa visión, el ciudadano se muestra en la arena pública ajustando su apariencia a la mirada del otro.

52 Protágoras 327b-d. Ferécrates fue un comediógrafo ateniense, contemporáneo de Cratino, Crates y Aristófanes, al que se le adjudican alrededor de dieciocho obras. Solo han sobrevivido unos pocos fragmentos de sus escritos y entre ellos los de su obra Ágrioi que fue presentada en las Leneas del 420. Sobre los fragmentos conservados, véase von Kassel y Austin (1983-2000). Al parecer, la pieza en cuestión representaba en escena a un coro de misántropos que abandonaban la civilización y entonces el autor se complacía al presentar diversas formas de vida primitiva contrastándolas con las de su época. Al respecto, véase Lesky (1963), p. 451.

53 Véase LSJ s.v. 'aischrós'. En el campo semántico del término aparece el verbo aischýnō ('deshonrar', 'avergonzar') y, derivado de él, el sustantivo aischýnē ('vergüenza', 'deshonor') que en varias oportunidades es usado, como ya hemos notado, con el valor de aidōs. Al respecto, véase Chantraine (1999), p. 40.

54 Puesto que la mayoría de los capítulos de los Dissoi Lógoi se inicia constatando que, sobre esas cuestiones, "existen discursos dobles", se los ha vinculado con Protágoras, quien, según el testimonio de Diógenes Laercio, habría escrito una obra titulada Antilogías y habría sido el primero "en sostener que sobre cualquier cuestión existen dos discursos mutuamente opuestos" (DK80 A1). Sobre la concepción protagórica de los "discursos dobles", véase Schiappa (1954), pp. 89-102. Con respecto a la discutida datación del opúsculo, véase Robinson (1979), pp. 34-41 y Conley (1985). 
del segundo capítulo de ese opúsculo (titulada Perí kaloû kaí aischroû), el autor pasa revista a una serie de ejemplos para demostrar que las cosas son o bellas o vergonzosas según la ocasión y, entre los argumentos que presenta, aparecen los siguientes:

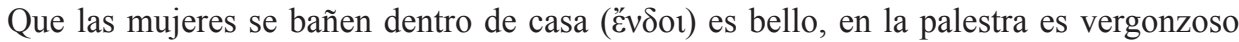
(aischrón) (§3). Hacer el amor con un hombre en la soledad (hasychíai), al amparo de las paredes, es bello; fuera (éxō), en donde se puede ver (ópou tis ópsetai), es vergonzoso (aischrón) (§4). Maquillarse, ungirse de perfumes y adornarse con joyas, en un hombre es vergonzoso (aischrón), en la mujer es bello (§6). Para los espartanos, que las muchachas hagan gimnasia y aparezcan en público (parérpen) arremangadas y sin túnica es bello, para los jonios es vergonzoso (aischrón) (§9). Para los tracios, que las muchachas se tatúen es un adorno, para los demás los tatuajes son el estigma de los culpables (DK90 $\S 13)^{55}$

Resulta claro que el autor pretende demostrar que nada hay absolutamente bello ni vergonzoso, sino que todo depende del ámbito en el que se actúe y, en ese sentido, opone espacios dentro de la ciudad, configurándolos del siguiente modo: por un lado, nos encontramos con un espacio de tipo privado, el del 'hogar', la 'soledad' y el amparo de las murallas; por el otro, con un ámbito de tipo público, el del 'exterior', la palestra, un espacio donde es posible 'ver'. Además, en paralelo a esas delimitaciones, el autor apela a la categoría de lo aischrós para señalar aquellos hechos y acciones que están en desacuerdo con los valores del espacio público. Podría deducirse que si un sujeto franquea lo privado, pretendiendo evitar la vergüenza, deberá acomodarse a lo establecido para no frustrar la expectativa de los otros: por ejemplo, maquillándose y adornándose con joyas si es hombre. De esta forma, queda claro que lo vergonzoso vuelve a estar en relación con los aspectos visuales de los agentes (tatuajes, maquillaje, adornos, vestuario y/o actividades) y con la mirada de los otros, que se activa toda vez que el agente ingresa en la esfera pública. Retomando el razonamiento protagórico, esos valores son aquellos que los atenienses inculcan a sus niños desde temprana edad: la sabiduría sobre las apariencias pertinentes.

La cuestión de las apariencias es, finalmente, subrayada por Protágoras en uno de los últimos argumentos sobre la participación de todos los ciudadanos en la arete política. El sofista explica a Sócrates que "incluso el que te parece (phaínetai) el hombre más injusto entre los educados en las leyes" (Protágoras 327c4-6) sería justo si se lo confrontara con los que nada saben ni de tribunales ni de leyes, como aquellos salvajes que 'enseñó' (didáskō, Protágoras 327d4) Ferécrates en las Leneas. Añade luego que si Sócrates se encontrara entre esos salvajes - i.e. en medio del coro de la comedia Ágrioi $-^{56}$ extrañaría a los hombres de su ciudad e incluso desearía toparse con Euríbato y Frinondas - dos conocidos delincuentes de la época.$-^{57} \mathrm{Y}$

55 La traducción le corresponde a Piqué Angordans (1985) modificada levemente siguiendo la edición de Diels y Kranz (1951-1952). Decidimos unificar criterios en la traducción de aischrós, pues si bien el traductor elige el término 'feo' en la mayoría de las ocasiones no lo hace, por ejemplo, en $\S 10$.

56 García Gual (1982, p. 534 n. 35), no duda en comparar al coro de la obra de Ferécrates con Pisetero y Evélpides, personajes centrales de la comedia Aves de Aristófanes, pues ambos casos parecen representar el afán utópico y escapista de ciertos misántropos que abandonan la vida de la ciudad en busca de una existencia idílica.

57 Protágoras 327d4-e1. Taylor (1976, pp. 97-8) y Divenosa (2006, p. 149 n. 85), señalan que Euríbato y Frinondas eran nombres de personas reales que se habían convertido en sinónimos de perversión. En Tesmoforiantes (v. 861), Aristófanes menciona el mismo nombre de Frinondas, y Balzaretti (2010, p. 118 n. 238), sugiere que en 
para cerrar su argumento, Protágoras le advierte que ahora goza de paz porque "todos son maestros de areté, en lo que puede cada uno, y ninguno te lo parece (kai oydeís soi phaínetai)" (Protágoras 327e1-3). Como puede notarse, el ejercicio mental que Protágoras propone implica equiparar, en primer lugar, el discurrir de Sócrates por la ciudad con un discurrir por la escena teatral y, en segundo lugar, a ciudadanos como Euríbato y Frinondas con personajes del coro de una comedia y, en ambos casos, las relaciones interpersonales se definen por los pareceres y apareceres.

El argumento comienza y concluye con usos del verbo phaínetai que ponen en evidencia la naturaleza anfibia de la phantasía de la que ya hemos hablado. En efecto, el sofista se refiere tanto al aparecer de los ciudadanos como al parecer de Sócrates $\mathrm{y}$, a la hora de corregir este último, apela a la representación de una pieza teatral. Si a Sócrates le parece que los ciudadanos de su pólis son injustos, debe compararlos con el aparecer de los personajes de Ferécrates para tomar real conciencia de la diferencia: estos son realmente injustos, mientras que aquellos participan todos aunque sea mínimamente - de la aretē. Podríamos decir entonces que, a los ojos del Abderita, el teatro guarda ciertas similitudes con las condiciones de la ciudad y que esas similitudes habilitan una equiparación no solo de sus personajes con los ciudadanos, sino también de su lógica de funcionamiento con la de la propia pólis. En un contexto en el que se ha insistido sobre las apariencias que deben sostenerse en determinadas situaciones y las miradas que evalúan dichas apariencias, el caso del teatro parece resultar paradigmático. ${ }^{58} \mathrm{Al}$ asistir al théatron, los ciudadanos atenienses se enfrentaban a una serie de apariencias que los actores proyectaban no solo ante la mirada de sus pares (personajes de la trama como ellos), sino ante la de todo un auditorio. Si la dinámica básica del drama suponía el uso de un disfraz mimético que sostenía la ilusión sobre la escena, el trabajo del actor representaba un claro ejemplo para el ciudadano que, desde la perspectiva protagórica, debía aparentar justicia en el espacio público. De esta forma, actor y ciudadano comparten una obligación elemental: ambos deben sostener sus apariencias si pretenden mantener su condición. El actor seguirá siendo actor en la medida en que sostenga su disfraz y el ciudadano seguirá siendo ciudadano, en la medida en que, en el espacio público, aparente participar de las convenciones de su ciudad.

Más allá de las lecturas que suelen detenerse en las preocupaciones sofísticas sobre el lenguaje y sus efectos, en este trabajo hemos querido resaltar un singular enfoque del Abderita que pone en evidencia el rol preponderante de lo visual en la praxis política de los atenienses. A nuestro juicio, dicho enfoque ha sido soslayado por los intérpretes, pero resulta clave a la hora de comprender el posicionamiento político que Protágoras despliega en el diálogo platónico homónimo. En tres momentos sucesivos de su Gran Discurso, el sofista deja entrever que la ciudad se sostiene en las apariencias y en los pareceres. En primer lugar, el mito presenta un panorama en el que no hay ciudad posible sin aidōs ni dikēe, lo que presupone la configuración de un espacio público atravesado por la mirada evaluadora de sus miembros y gobernado por las apariencias que cada uno de ellos proyecta, apariencias que deben reproducir los valores comunales. En segundo lugar, Protágoras subraya que, en ese ámbito y ante la mirada atenta de sus pares, los ciudadanos deben aparentar ser justos, lo sean o no, pues de lo contrario corre riesgo su lugar en la comunidad. En tercer

Atenas tal nombre era proverbial y equivalía a "villano" y "delincuente".

58 Sobre el lugar de la poesía toda en el pensamiento del Abderita, véase DK80A28 y A29. 
lugar, el sofista advierte que los límites de lo vergonzoso (i.e. los límites tanto de lo que se proyecta como de lo que se evalúa) son incorporados en los niños desde su instrucción inicial, y finalmente equipara el aparecer de los ciudadanos en el ámbito público con el aparecer de unos personaje cómicos en la escena teatral. ${ }^{59}$

En suma, los pilares de la ciudad protagórica no son otros que las apariencias y los pareceres de sus miembros, y esta lectura de la praxis política complementa aquel silencio que le adjudicamos al sofista. En efecto, si esa actitud respecto del plano ontológico suponía una prioridad de la phantasía allende la existencia de un objeto al margen del fenómeno, la lectura política implica que, más allá de la condición efectiva de los ciudadanos, lo prioritario es su aparecer como justos, las apariencias se desentienden de cualquier instancia trascendente que queda así en un estado de silencio e indeterminación. Podría pensarse que si la ciudad se sostiene sobre meras apariencias y si además lo que a cada ciudad le parece justo puede variar de manera indefinida, ${ }^{60}$ aquellos pilares se hunden en la precariedad y en la incertidumbre, ${ }^{61}$ pero el rol de la aidōs y la amenaza del castigo operan contra esa incertidumbre. Mientras que la aidōs supone una mirada inquisidora que vigila las apariencias de todos y extiende de manera indefinida el ámbito público que parece configurarse allí donde una mirada se posa sobre una acción ajena, las figuras de la otredad y la locura se mantienen en el horizonte como amenaza constante frente a una eventual violación del principio rector de la ciudad: aparecer como justo de manera incesante.

\section{Referencias bibliográficas}

Adam, J. y Adam, A. (eds.) (1905): Platonis Protagoras, Cambridge, CUP.

Arieti, J. y Barrus, R. (2010): Plato's Protagoras, Plymouth, Rowman \& Littlefield Publishers. Balzaretti, L. (2007): Aristófanes. Aves, Buenos Aires, Editorial Losada.

Benveniste, E. (1969): Le Vocabulaire des institutions indo-européennes. II. Pouvoir, droit, religion, Paris, Minuit.

Boeri, M. (2006): Platón. Teeteto, Buenos Aires, Losada.

Bonazzi, M. (2012): "Il mito de Prometeo nel Protagora: una variazione sul tema del origini", en Calabi, F. y Gastaldi, s. (eds.), Immagini delle origini. La nascita della civiltà e della cultura nel pensiero antico, Sankt Augustin, Academia Verlag, pp. 41-57.

Brisson, L. (1975): "Le mythe de Protagoras. Essais d'analyse structurale", en Quaderni Urbinati di Cultura Classica, 20, pp. 7-37.

Cairns, D. (1993): Aidōs. The Psychology and Ethics of Honour and Shame in Ancient Greek Literature, Oxford, Clarendon Press.

59 Podría considerarse, aunque no podrá ser objeto de un tratamiento suficiente en estas páginas, que Protágoras ofrece un enfoque de tipo performativo sobre la política ateniense. Al respecto, puede consultarse la propuesta de Goldhill (1999, pp. 1-23), para quien un término como performance representa una categoría heurística clave para explorar los valores y las áreas de actividad fundamentales de la cultura democrática ateniense. En ese sentido, delimita conceptualmente su propuesta por medio de cuatro términos propios del mundo griego como agón, epídeixis, skhêema y theóría y por cuatro nociones generales como las de espectáculo (que ilumina el funcionamiento de las instituciones clave de Atenas), audiencia, construcción del sí-mismo y auto-conciencia. Téngase en cuenta que si bien Cassin (1995) vincula el concepto de performance con la sofística, lo hace considerando el "efecto mundo" que, para esos sofistas, tiene el lógos debido a su capacidad para transformar, "performar", el mundo.

60 Véase Teeteto $167 \mathrm{c}$.

61 Al respecto, véase Gallego (2003), pp. 322, 334-44 y 389. 
Calame, C. (2012): “The Pragmatics of “Myth" in Plato's Dialogues: The Story of Prometheus in the Protagoras", en Collobert, C., Destrée, P. y Gonzalez, F. (eds.), Plato and Myth. Studies on the use and status of Platonic Myths, Leiden, Brill, pp. 127-44.

Capizzi, A. (1955): Protagora: le testimonianze e i frammenti, Firenze, G. S. Sansoni.

Cassin, B. (1994): “Del organismo al picnic. ¿Qué consenso para qué ciudad?”, en Cassin, B. (ed), Nuestros griegos y sus modernos. Estrategias contemporáneas de apropiación de la antigüedad, Buenos Aires, Manantial, pp. 85-107.

Cassin, B. (1995): L'effet sophistique, Paris, Éditions Gallimard.

Chambry, E. (1967): Platon. Protagoras, Paris, Garnier-Flammarion.

Chantraine, P. (1999, 1968): Dictionnaire étymologique de la Langue Grecque. Histoire des mots, (terminé par O. Masson, J.-L. Perpillou, J. Taillardat, avec le concours de F. Bader, J. Irigoin, D. Lecco, P, Monteil, sous la dir. de M. Lejeune), CNRS, Paris, Klincksieck.

Classen, C. (1989): "Protagoras Aletheia", en Huby, P. \& Neal, G. (edd.), The Criterion of Truth. Essays written in Honour of George Kerferd, Liverpool, pp. 13-38.

Conley, T. (1985): "Dating the So-Called Dissoi Logoi: A Cautionary Note", en Ancient Philosophy 5, pp. 59-65.

Croiset, A. y Bodin, L. (trads.) (1948): Platon. Protagoras, París, Les Belles Lettres.

Decleva Caizzi, F. (1999): "Protagoras and Antiphon: Sophistic debates on justice", en Long, A. A. (ed.), The Cambridge Companion to Early Greek Philosophy, Cambridge, CUP, pp. 311-31.

Denyer, N. (2008): Plato: Protagoras, Cambridge, CUP.

Díaz, M., Livov, G. y Spangenberg, P. (2009): "Una introducción a la phantasía antigua", en Marcos, G. y Díaz, M. (eds.), El surgimiento de la phantasía en la Grecia Clásica. Parecer y aparecer en Protágoras, Platón y Aristóteles, Buenos Aires, Prometeo Libros, pp. 27-40.

Diels, H. y Kranz, W. (1951-19526): Die Fragmente der Vorsokratiker, Berlin, 3 vols.

Divenosa, M. (2006): Platón. Protágoras, Buenos Aires, Losada.

Dougherty, C. (2006): Prometheus, New York, Routledge.

Gallego, J. (2003): La democracia en tiempos de tragedia: asamblea ateniense y subjetividad politica, Buenos Aires, Miño y Dávila Editores.

García Gual, C. (1982): Platón. Protágoras, Madrid, Gredos.

Goldhill, S. y Osborne, R. (edd.) (1999): Performance culture and Athenian Democracy, Cambridge, CUP.

Gottesman, A. (2014): Politics and the Street in Democratic Athens, Cambridge, CUP.

Goux, Jean-Joseph (1990): Oedipe philosophe, Ed. Aubier (citamos según trad. esp. de Pinkler, L. (1999): Edipo Filósofo, Buenos Aires, Editorial Biblios).

Grimaldi, W. (1988): Aristotle. Rhetoric II. A Commentary, New York, Fordham University Press.

Guthrie, W. (1956): Plato: Protagoras and Meno, Harmondsworth, Penguin Books.

Guthrie, W. (1969): A history of greek philosophy. Volume III: The fifth century enlightenment, Cambridge, CUP (citamos según trad. esp. de: Rodríguez Feo, J. [1994]: Historia de la filosofía griega III. Siglo V. Ilustración, Madrid, Gredos).

Havelock, E. (1957): The Liberal Temper in Greek Politics, New Haven, Yale University Press.

Ildefonse, F. (1997): Platon. Protagoras, Paris, Flammarion.

Jiménez, A. (2000): Hesíodo: Obras y Fragmentos, Barcelona, Editorial Gredos.

Kerferd, G. (1981a): The Sophistic Movement, Cambridge, CUP

Kulesz, O. (2009): “La phantasía en el pensamiento preplatónico. Una ruta hacia el Protágoras 
historico", en Marcos, G. y Díaz M. (eds.), El surgimiento de la phantasía en la Grecia Clásica, Buenos Aires, Prometeo, pp. 41-67.

Lesky, A. (1963): Geschichte der griechischen literatur, AG Verlag (citamos según trad. esp. de: Díaz Regañon, J. y Romero B. (1989): Historia de la literatura griega, Madrid, Gredos).

Manuwald, B. (1999): Platon. Protagoras. Übersetzung und Kommentar, Göttingen, Vandenhoeck \& Ruprecht.

Manuwald, B. (2013): “Protagoras' Myth in Plato's Protagoras: Fiction or Testimony?", en van Ophuijsen, J., van Raalte, M. y Stork, P. (eds.), Protagoras of Abdera: The Man, His Measure, Leiden, Boston, pp. 163-78.

Mansfeld, J. (1981): "Protagoras on Epistemological Obstacles and Persons", en Kerferd, G. (ed.), The sophists an their legacy. Proceedings of the fourth international colloquium on ancient philosophy at Bad Homburg 1979, Wiesbaden, pp. 38-53.

Melero Bellido, A. (1996): Sofistas. Testimonios y Fragmentos, Madrid, Gredos.

Mondolfo, R. (1955): La comprensión del sujeto humano en la cultura antigua, Buenos Aires, Eudeba.

Morgan, K. (2000): Myth and Philosophy from the Presocratics to Plato, Cambridge, CUP.

Nestle, W. (1944): Griechische Geistesgeschichte von Homer bis Lukian. In ihrer Entfaltung vom mythischen zum rationalen denken dargestellt, Stuttgart, Kröner (citamos según trad. esp. de: Sacristán, M. [1975]: Historia del espiritu griego. Desde Homero hasta Luciano, Barcelona, Ariel).

Robinson, T. (1979): Contrasting Arguments: An Edition of the Dissoi Logoi, New York, Arno Press.

Rodríguez Adrados, F. (1975): La democracia ateniense, Madrid, Alianza Editorial.

Rodríguez Adrados, F. (dir.) (1980ss.): Diccionario Griego-Español, Madrid. (DGE)

Rossetti,L.(1985): "L'aisthesis come referente ultimo in Protagora: peritrope e 'antiperitrope"”, en Capasso M., De Martino F. y Rosati P. (eds.), Studi di filosofia preplatonica, Napoli, Bibliopolis, pp. 173-190

Piqué Angordans, A. (1985): Sofistas. Testimonios y fragmentos, Barcelona, Bruguera.

Poratti, A. (1999): “Teoría política y práctica política en Platón”, en Boron, A. (comp.), La filosofía política clásica: de la Antigüedad al Renacimiento, Buenos Aires, CLACSO, pp. 17-57.

Saxonhouse, A. (2006): Free Speech and Democracy in Ancient Athens, Cambridge, CUP.

Schiappa, E. (1954): Protagoras and logos. A study in Greek Philosophy and Rhetoric (2. ${ }^{a}$ ed.), Columbia, University of South Carolina Press.

Solana Dueso, J. (2000): El camino del ágora: filosofía política de Protágoras de Abdera, Zaragoza, Prensas Universitarias de Zaragoza.

Solana Dueso, J. (2011): "Protágoras y los poetas", en Convivium, 24, pp. 5-24.

Sørensen, A. (2016): Plato on Democracy and Political technē, Leiden, Brill.

Spangenberg, P. (2009): “Phantasía y verdad en Protágoras", en Marcos, G. y Díaz M. (eds.), El surgimiento de la phantasía en la Grecia Clásica, Buenos Aires, Prometeo, pp. 69-98.

Sprague, K. (ed.) (1972): The older sophist, Columbia, University of South Carolina Press.

Tangney, J. (1991): "The Moral Affect: The Good, the Bad, and the Ugly", en Journal of Personality and Social Psychology, 61, pp. 598-607.

Taylor, C. (1976): Plato, Protagoras. Revised Edition, Oxford, OUP.

Untersteiner, M. (1949-1967): Sofisti. Testimonianze e frammenti, Florencia, La Nuova Italia, 4 vols. 
Van Riel, G. (2012): “Religion And Morality. Elements Of Plato's Anthropology in the Myth Of Prometheus (Protagoras, 320D-322D)", en Collobert, C., Destrée, P. y Gonzalez, F. (eds.), Plato and Myth. Studies on the use and status of Platonic Myths, Leiden, Brill, pp. 145-64.

Versenyi, L. (1962): “Protagoras' man-measure fragment”, en American Journal of Philology, 83, pp. 178-184.

von Kassel, R. y Austin, C. (1983-2000): Poetae Comici Graeci, Vol. 7, Berlin, De Gruyter. Williams, B. (1993): Shame and Necessity, Berkeley, University of California Press.

Zilioli, U. (2007): Protagoras and the Challenge of Relativism. Plato's Subtlest Enemy, Hampshire, Ashgate. 